Word count: 6813 incl refs.

\title{
Holding it all together: Breast cancer and its impact on life for younger women
}

Received 10 May 2006

Accepted 19 October 2006

Elisabeth Coyne

Associate Lecturer

School of Nursing and Midwifery

Griffith University - Logan Campus

Meadowbrook QLD, Australia

Sally Borbasi

Professor

School of Nursing and Midwifery

Griffith University - Logan Campus

Meadowbrook QLD, Australia

\section{Abstract}

While breast cancer is often associated with older women, in the year 2000, $25 \%$ of new breast cancer diagnoses in Australia affected young women. An interpretive study using in-depth interviews provided valuable insight into the lived experiences of six young Queensland women living with breast cancer. This paper presents data from the study with a particular focus on young women and the impact it has on their social situation and their family. The young women in this study found a diagnosis of breast cancer traumatic and their responses were heightened as they sought to understand why at such a young age. For the younger woman a diagnosis of breast cancer is likely to cause not only emotional distress but concerns relating to motherhood, family and fertility. In many respects younger women having greater responsibility for the well being of others in their family and in the provision of stability for everyday family life face a tough reality than older women with breast cancer. 
This study identified that a specialist breast care nurse is an important resource.

\section{Key words}

Young women; premenopausal; breast cancer; family; qualitative

\section{Introduction}

The publicity afforded breast cancer is a growing phenomenon especially when it affects the lives of high profile people and their immediate family. Over the last decade efforts to raise funds for research into this troubling disease have heightened public awareness and 'pink ribbons' are now knowingly associated with women and their struggle against this particular cancer. In many cases it is younger women who capture the public's imagination as in recent examples in Australia including a high profile popular singer, Kylie Minogue and Jane McGrath, wife of a national cricketer. Despite recognition of the prevalence of breast cancer; 25\% of breast cancer diagnoses are in women under 50 years yet there has been little research that explores the consequences of breast cancer on young women and their families (Dunn \& Steginga 2000; Raveis \& Pretter 2004). In addition, the literature that is available largely explores the experience of breast cancer from quantifiable survey data lacking therefore a deep authentic perspective on the event as it is lived.

\section{Literature review}

Breast cancer is the most common cancer diagnosis among Australian women, affecting approximately 11791 women in the year 2001 (Australian Institute of Health and Welfare AIHW 2005). While the reported incidence has increased due to improved screening and early detection, treatment has led to an increase in survival. More women with a diagnosis of breast cancer are living longer and the disease has come to be regarded as chronic rather than terminal (AIHW 2005; National Breast Cancer Centre NBCC 2001a).

Up to 25 percent of women diagnosed with breast cancer are of childbearing age (AIHW 2005; Thewes \& White 2005) thus potentially affecting a large number of 
children and family units. Although all women with breast cancer may share common concerns a number of studies which have included women from the younger age group have shown that younger women experience heightened levels of anxiety and stress with diagnosis than older women (Bloom et al. 2004; Dunn \& Steginga 2000; Hoke 2000). A factor attributed to the different psychosocial life stage occupied by younger women (Coyne 2004; Dunn \& Steginga 2000).

Young women's lives more commonly involve multiple roles including being mother to dependent children, spousal and domestic duties and participation in paid work. Previous research has identified certain risk factors associated with increased psychosocial vulnerability upon diagnosis of breast cancer. These include being under the age of fifty, being single, living alone, having little social support and having children under the age of 21 years (NBCC 2001b; Parle et al. 2001). A descriptive study by Parle et al. (2001) examined 196 female breast cancer patients with a mean age of 56.4 years. The women filled out a general health questionnaire designed to identify clinical psychological difficulties. The survey showed that over a third of the women experienced significant psychological distress. Parle et al. (2001) compared those findings with a survey of the rate of detection of women's psychological distress by special breast nurses. This arm of the study demonstrated a low rate of detection and referral by breast care nurses, especially of women in the younger age group. The Parle et al. (2001) study highlights the importance of appropriate assessment of psychological sequelae by health professionals especially among younger women.

To date there has been limited research relating specifically to young women with breast cancer (Dunn \& Steginga 2000). Most studies that collect data on the younger age group do so as part of examination of a broad age group normally from 25-70 years often with a mean age group around 55 years (Parle et al. 2001; Steginga et al. 1998). Specific concerns identified in earlier research have related to the phase of life of younger women, which is premenopausal. The disruption of ovarian function with resultant clinically induced menopause and infertility and the subsequent psychological sequelae of anxiety and distress are reported consistently in research (Graf \& Geller 2003; Knobf 2001). 
To add to the complexity of adjustment to the impact of breast cancer a young woman, who maybe a mother is often required to change roles especially with regard to caring for younger children during her breast cancer treatment when periods of hospitalisation and personal debilitation occur (Turner et al. 2005; Walsh, Manuel \& Avis 2005). Previous research has identified that changing roles and functions within a family unit is disruptive and causes anxiety for all members (Northouse 2005; Walsh et al. 2005).

The literature focuses on participants from a broad spread of ages not specifically women under the age of fifty years. Moreover these predominately quantitative studies provide little perception of this life changing experience for younger women as they face the disease and its bodily consequences. The qualitative study reported here sought to produce a more socially relevant and effective representation of the phenomenon of breast cancer in younger women; addressing the lack of personal insight to extant literature. Enabling women to tell their stories ensures health professionals have an increased understanding of their concerns.

\section{Aim of the study}

This paper reports aspects of findings from a study that set out to explore the experience of a diagnosis of breast cancer for women under the age of fifty. In particular the researcher wanted to explore the psychosocial support needs of younger women with reference to their phase of life and family concerns. The significance of this study was to document areas the younger women themselves saw as important. Also to highlight aspects which the women thought could be changed relating to their treatment to make it easier for them as young women. In this paper the focus is on the experience surrounding diagnosis; the consequences of diagnosis on family; and the experience of life after diagnosis and early treatment.

\section{Methodology}

The study was interpretative drawing on understanding from feminist inquiry and set out to identify and describe experience through the telling of women's stories (Emden 1998). This was seen as a valuable means to achieving a deeper and richer 
appreciation of the emotional complexities surrounding what it means to have breast cancer as a younger woman and consequences on social life (Porter 1998).

In keeping with feminist traditions the method of data collection utilised in-depth interviews and a participatory research process. The researcher established rapport with the participants prior to the interview; listened actively and encouraged the women to speak openly without the constraints imposed by set questions (Reinharz 1992). In effect, the researcher allowed the women to control the flow of the interview with little direction (Glesne 1999). This approach attempted to understand the women's place in the world and enabled the complexity of experience/s to be explored and the focus to be on the actual journey through illness (Lather 1991).

Having obtained written consent each interview was conducted in the woman's home at a time of convenience. Interviews were tape recorded and later transcribed verbatim. A more formal counselling service was offered. Transcriptions were verified by the participants, there were no requests for change from the women.

\section{Ethics}

Ethical approval was granted by the University of Southern Queensland Human Research Ethics Committee and participating private hospital Ethics Committee. A written information sheet was explained to the participant and the consent form was signed prior to the interview.

\section{Participants}

Six women with a diagnosis of breast cancer in the previous 12 months completed the interviews. The women comprised a purposive sample and volunteered to participate after hearing an information session provided at a private hospital in Brisbane. The participants were all English speaking. Each participant chose a pseudonym to ensure anonymity. See Table 1 for further demographic data. The disease status for the women was varied; the participants experienced a range of different treatments; surgery, chemotherapy and radiotherapy. The participants had suffered debilitating symptoms from the chemotherapy such as nausea, fatigue and hair loss. One woman who was pregnant had not yet begun treatment beyond surgery. 
$<$ PLACE TABLE 1 HERE $>$

\section{Data analysis}

Using thematic analysis as described by Strauss and Corbin (1990) the transcripts were read completely several times to gain a sense of meaning (understanding). Themes and categories were formulated through a process whereby key theme sentences from all of the transcripts were grouped into categories. Categories identified specific experiences consistent among the participants highlighting their significance for the women. Overarching themes extrapolated from the data and explored in this article were: diagnosis - having to be strong; impact on the family; life after treatment. In keeping with the study's epistemology the analysis sought to accurately interpret the women's experience and meanings while providing precision and breadth (Becker 2005). No attempt is made to generalise the results, each social actor's account of the world is considered their own explanation and not fixed. It is the abstracted patterns and commonalities within and across the totality of detail; those shared understandings of human experience (Holloway \& Wheeler 2002) that are presented here.

\section{Findings}

\section{Diagnosis - having to be strong}

For the women in this study it appeared a shock to learn they had breast cancer; the actual point of diagnosis was described as the most stressful time in their lives. Too young to have cancer; they became forced to examine their views on femininity as well as confront a myriad of concerns presented by such a frightening reality. Women spoke of the turmoil they experienced during those early days and ensuing weeks. They described their inner self as being on an emotional rollercoaster with numerous lows and highs as the differing phases of treatment were passed through. During this time they found significant comfort in family relations and close friendships:

... no-one can prepare you for the emotional impact of it, you know...that was very hard for me, all of that. ...I've had a wonderful support network. Dawn 
However these relationships came at a price as the women talked of the emotional labour they were required to expend in outward displays of courage and positive coping in order to shield their families and friends from the distress of it all.

I found that you just get over one thing and there would be something else you have to deal with. And having to climb back up there again and I really felt that I just had to be so strong and hold it together for my family. While I was okay then they would be okay. Anne

At times the women just wanted to be able to relax (let down their guard) and be 'mothered'. Family is assumed the main support however the women revealed this is not always the case. Dawn was upset her mother perceived the diagnosis as terminal:

I needed her to be my Mum and just [mother me]... but she saw me as having one foot in the grave. That's what I despised the most. Dawn

For three of the women family support was not forthcoming because a parent actually suffered serious illness during the time of the woman's diagnosis and treatment. This meant the women were required to provide concerned attention rather than receive it further complicating the family’s situation.

[I] was waiting for the radiotherapy to start. In the meantime my mum had the stroke. So I was spending my life running after her. ...it was like trying to walk up a hill. I went to the hospital with her but I really didn't have time to think about myself, it's just a case of getting her sorted out and then getting her into rehab and doing all those things that you have to do. Joan

Participants spoke of ongoing anguish as they became faced with more and more of the ramifications associated with breast cancer and its treatment. For example, at some point they had to face the prospect of becoming menopausal. Struggling with the unfairness of it the women rallied against a cancer that had taken away their choices in life - replacing them instead with constant worry over the future. 
...in one fell swoop I was told that everything that was feminine to me was gone. I was losing my breast, I possibly couldn't have children - they were big things... women are meant to have children. It's all right if you choose not to have them, but to be told you can't have them... all of a sudden, my choices for my life...everything I had planned were being taken away from me. Dawn

Finding humour in certain situations with the help of women who also had breast cancer (breast cancer support groups) often reduced the women's fears and assisted them to move through stressful events. Pat regularly attended the young women's group and shares her thoughts:

It was funny and tragic at the same time. ...They were just a hilarious bunch of girls. One young girl who was in her 20s, she had lost her fertility; she was joking she got to go through menopause at the same time as her mother! I remember standing about one night and we were doing the top ten reasons for going through chemo!... So no, I don't think I would have got through without them..

Women had to make changes in their lives to accommodate the after effects of chemotherapy. Anne described life at that time:

There would be like a week where I'd be pretty well ironed out plus the following weekend and I couldn't really cope with the girls all day and a friend, their godmother would take them to the movies on a Saturday afternoon, just for a couple of hours, just to break it up. So then the next week I would kind of surface a little bit more. Then the third week, I'd be okay and that's when I'd do my running about and make appointments and have a chat with people. But I didn't drive for that first ten days, my head was so funny. I didn't feel safe to drive.

The Specialist Breast Nurse was described as an excellent resource by the women who had access to one. However only 2 of the six women had continued contact with the Specialist Breast Nurse.

... she was the expert. She told me what would happen and it did. Anne 
Fay highlights the need for a family centered approach to lessen not only her burden in worrying how the family was coping but her partner's burden in keeping the family afloat. She explains:

It would [have been] nice if someone had come to him and said 'How are you coping'?

The Support Group was planning a social event for members and Fay questioned: Why can't we have something in dedication to our partners? ...they have gone through a lot ..

\section{Impact on the family}

The complex interplay between having breast cancer and being a mother was cause for significant stress and emotional suffering for the women in this study, particularly if the children were very young. Women described concerns about how to explain the breast cancer diagnosis to their children and the limited information available to parents to assist in this difficult task.

We had explained to them [the children] before we went in and they [the breast clinic staff] actually gave me a book written for kids ...it was okay but I have always wanted to write another one for them to truly understand... Fay

Anne recalls the experience of telling her children and highlights the emotional trauma her family went through.

My eldest daughter [11 years] said to me, 'When were you going to tell us?' and I said, 'Well, you knew that I was going to have to go to hospital and have something cut out.' I said, 'I couldn't tell you, I told you as much as I knew.'

We'd just been to see the specialist and so I knew what was going to happen and what the time frame was going to be.

Her first question was a classic that I had read about. She said, 'Will I catch it; can I catch it?' I said not whereupon she came straight over and gave me a hug... Before then she hadn't wanted to come near me. 
While striving to be open and honest with their children again the women felt compelled to shield them from the depth of emotional trauma the discovery of breast cancer had caused her partner and herself. Typical comments included:

...it was difficult sometimes because you don't want to show those emotions in front of your children in case they get upset. Fay

Despite the relatively short length of stay in the hospital, none of the women expressed anything other than pain at the memories of the specialist oncology wards within which they received treatment for their cancer. Women with children were especially guarded and expressed an urgency to shield their children from what they perceived to be the horrors of it all. Pat's reveals her feelings:

The oncology wards are so awful ...everybody's so sick. I didn't want them [the children] to come in.

During a subsequent visit to hospital Pat found herself in another ward and expressed relief and pleasure 'not to be in oncology'. For her:

Where you are in the hospital makes a lot of difference to how you are feeling in yourself.

The women spoke of how they had encouraged their children to voice their concerns and discuss openly what was happening. However they continued to worry about their children's emotional needs and how they were going to assist them through the course of the disease. While spouses and partners also needed emotional assistance it was the children's well being that occupied most of the women's concerns. Pat illustrates how life was for her:

..because I am trying to be strong and everyone was doing really well and my kids were just so lovely... that was quite nice and we learnt a lot and we got a lot closer. I had days when I would cry but I made sure they saw me cry. I'd say it's okay I'm just having a sad day. It was all right for them to cry too. 
...but it was always my biggest worry I suppose...even though it must have been really awful for my husband I sort of knew that there were things he could do...there were people he could access and I told him that...he was big enough and old enough to decide what he wanted to do- whereas my kids couldn't.

For many women thinking about their children's future brought significant emotional distress which they often suffered in silence. Anne described her reality:

I'd lay there awake at night and I'd think - financially, how are we going to cope?... I was thinking 'Oh I could die' or there were times there that I was saying 'Wouldn't it be good if they actually had said that I had a terminal illness and that I only had 3 months or 6 months to live' and I would get my half a million payout and you know be debt free...

My children were my biggest thing but how were they going to cope through all this ...I still doubt whether they've coped. ...that was really hard.

Joan, Pat and Anne had slightly older children 8-15 years and spoke of how their children had confidence in their parents that everything would be okay but only as long as life for them continued as normal. Maintaining the routine became an important part of coping with the treatment and was reliant on family and friends to provide assistance with childcare and give the women time to recuperate from treatment.

\section{Life after treatment}

The women spoke of life after therapy pointing out that even then the family remained on an emotional rollercoaster. Pat remembers coming home from her final treatment:

We came home and that's when everything really fell apart. The whole family fell in a heap. We thought we were going to be fine now everything was finished...but it hit us all really hard. 
The effects of compounding stress leaves the family vulnerable as they try to remain focused on living a normal life and returning to balance again. She went on to say:

Our oldest was starting high school and that was hard to cope with. I used to be out the front waiting for him to come home. I've never been like that before with my kids and it was a big adjustment for him. It was really hard.

A long overdue but traditional family holiday was the defining moment for Pat.

That for me was virtually the turning point. I was eating whatever I wanted to eat. We bushwalked and I could do the big climbs that we had done in the past. I felt like a normal person again.

Fay's inner resolve to beat her cancer was obvious as she spoke of her uncertainty having reached what was potentially for her, the end of her breast cancer treatment:

I'm really scared now because I don't know what I'm going to do. It's like life after cancer what do you do and how do you live without that cause? I've lived my last 12 months with this and it's hard to go back to life the way it was. It was like a project - my project of how do I get through it? Where do I have to go? and that's how I will cope I will just focus on what I've got to get through; but there will be one day where the cancer journey is finished. At that point I will probably just break down....

Fay further illustrates strain on the family. As her treatment came close to the end she recalls an incident with her partner:

He turned around and said to me, Eeverything's you - you only think of yourself and you're being so selfish.' And I'm going, 'Well hang on ... where did that come from'? because ... I didn't see it as being that way ...but I think what happened was - through the whole lot the focus was all on me...But in his eyes ...he had to look after the kids... and me and worried about me [was I going to get better] and all those type of things... He found that really hard to cope with. 
The women in this study were essentially optimistic about their future - seeing survival as a challenge and a dire need to 'just get on with life'. Pat had joined a Dragon Boat team, which she felt was another positive turning point in her life. The women described how they now appreciated the 'little things' in life. Pat explained:

I remember being really conscious that I wanted to be really fit. I was walking and exercising a lot. I can remember when I was walking being so worried I was going to get hit by a car. I'm going to beat the cancer; it's not going to get me; better not be run over by a car.

I can just remember how incredible it was just to feel the sun on your skin; how good it was to be alive.

\section{Discussion}

This study has provided an understanding of the young women's experience of breast cancer and implications such a diagnosis has on self and family. The findings suggest that young women experience acute distress on diagnosis yet are required to retain a positive outlook for the sake of the family often with no emotional outlets for themselves; a state of being that only adds to the mental exhaustion commonly expressed by the participants. This is similar to findings from other research identifying that young women conceal their true feelings in order to stay positive (Bloom et al. 2004). The young women also identified fears about not surviving to see their children grow; increasing their emotional distress (Dunn \& Steginga 2000).

The women in this study explained that the breast cancer experience affects their family and they struggled to preserve family life while juggling pressures brought about by a rigorous treatment regimen. Larger studies with a broad age range have identified this finding in the younger cohort of women (Mellon \& Northouse 2001; Northouse et al. 2005). Another concern for younger women is that the breast cancer and its treatment take away choices in life especially regarding fertility. The family is forced to refocus future life aspirations which is emotionally draining and other research has suggested that support needs to be directed at assisting the family during this time (Bloom et al. 2001; Dunn \& Steginga 2000). Although body image and 
femininity were important to the younger women menopausal symptoms were their main concern partly due to a lack of information on the subject and its perceived impact on their fertility.

This study suggests that an understanding of appropriate support mechanisms to reduce stress and anxiety are important considerations in improving the lives of young women. Strong family support has been shown to assist women to maintain a positive, confident self image enabling them to better adjust (Bloom et al. 2001; Cohen, Kahn \& Steeves 1998; Coyne 2004). While individuals will draw on differing coping strategies during the treatment regime and beyond it is important for health professionals when caring for younger women with breast cancer to identify and respond to each family’s individual needs (Coyne 2004; Epping-Jordan et al. 1999; Hutchinson, Steginga \& Dunn 2005; NBCC 2001b). Of importance to service providers is the recognition that the family's ability to successfully problem solve has been shown to reduce maternal anxiety and depression assisting the woman to remain functional in the maternal role and reducing the potential for psychological distress in her offspring (Compas et al. 1996; Hoke 2000).

Given all of the factors outlined thus far it is hardly surprising that young women with breast cancer have a greater tendency to anxiety, depressed mood and affective problems which can occur for up to two years after diagnosis; a situation recognised for its potential to impact negatively on the family particularly those with young children (Compas et al. 1994; Davis Kirsch, Brandt \& Lewis 2003; Parle et al. 2001). Parenting by mothers experiencing significant depressed moods and disrupted routines has been shown to have a detrimental affect on children's well being and family life (Davis Kirsch et al. 2003; Hoke 2000; Shands, Lewis, \& Hooper 2000; Turner et al. 2005). In relation to children's distress when their parent has cancer, the age and gender of the child has been found to impact on the severity of symptoms of anxiety and depression, adolescent girls in particular report more symptoms when their mother has cancer (Compas et al. 1994, 1996). Several of the women in this study reported feeling stressed in reference to their children's responses.

A number of the women referred to the breast cancer journey as an emotional rollercoaster presenting a number of highs and lows as they progressed through their 
treatment (Coyne 2004; Davis Kirsch et al. 2003). Specific issues with which the family must deal relate to the mother's reduced ability to assist children in previously taken for granted activities such as school pick up, homework and sporting schedules. Aspects of daily life are made difficult when the mother is struggling to cope with an aggressive treatment schedule complicated by emotional distress and fatigue from physical symptoms (Davis Kirsch et al. 2003; Dunn \& Steginga 2000). The potential for financial difficulty and anxiety about child care are added concerns (Coyne 2004; Hoke 2000). The consequences of breast cancer influence the family life and decisions throughout the active treatment phase but also in the survival phase after treatment.

An important finding from this research was the negative affect of hospitalisation on the young women; they described high levels of stress in relation to their children's anxiety during their acute treatment phase and lack of child friendly facilities. Few acute health providers offer child friendly services yet research has identified their importance in dealing with families (Coyne 2004; Wilkes, White \& Beale 2002). Moreover there have been few empirical studies that have examined how young families cope with the experience of maternal hospitalisation. Research however has identified that task oriented health professionals do not adequately cater to the family's needs during hospitalisation (Coyne 2004; Turner et al. 2005; Wilkes et al. 2002) making it difficult for the family, especially those with younger children, to visit in a manner that is mutually beneficial (Coyne 2004).

The increased risk of psychosocial problems among younger women with this disease and their families is significant. The support and advice provided by a trained Specialist Breast Nurses is a positive and practical solution to the need for expert help during this difficult time, an important component being advice on how parents can talk to their children about the illness and its impact on their lives (Davis Kirsch et al. 2003; Liebert et al. 2001; NBCC 2001b , 2003). The women in this study with support from a Specialist Breast Nurse described this as a very positive and supportive relationship consistent with Leibert et al.’s (2001) research regarding Specialist Breast Nurses. 
The young women in this study questioned why they have been diagnosed with breast cancer when so young but finding meaning and positive coping strategies assisted them in their breast cancer journey. In addition, as suggested in this study, humour has been reported to improve women's sense of well being and relaxation during periods of high stress (Johnson 2002). Humour also eases the burden when children are involved allowing them to feel more comfortable with a situation and thereby improving their ability to cope with stressful events such as hospital visitation (Compas et al. 1996; Coyne 2004). Supporting women's spirituality has been found to be helpful in assisting her to find meaning and move through the breast cancer trajectory (Henderson et al. 2003).

It has been suggested that over time women adjust to the diagnosis of breast cancer, find new meaning in their lives, regain a sense of control and eventually regain their self esteem (Rogers-Clark 2002) however studies on long term survivorship are few and far between. This study has shown the presentation of such an unexpected and alienating alternative life trajectory forced women to strongly resist the changes that cancer threatened to impose on life for them and their family. The positive and resilient nature of these younger women when faced with adversity was clear; all expressing determination in dealing with the experience. It may well be that a sense of having 'to be strong for the sake of children' together with strong maternal instincts to survive give younger women greater resilience in dealing with the ramifications of this public yet feared disease (Carver et al. 2005; Coyne 2004). Previous research has drawn attention to the positive resilience found in younger women (Dunn \& Steginga 2000; Turner et al. 2005) suggesting that health professionals should focus on this strength when working with the family towards recovery.

\section{Implications for nursing practice}

This paper has provided meaningful insight into the experience of breast cancer for young women and their psychosocial needs in relation to their family. The findings from this study highlight the need for health professionals to be cognisant of the important role family plays in the women's well being and include the family more thoroughly in the woman's care trajectory (Mellon \& Northouse 2001). The family’s strengths and resources should be assessed with guidance and support aimed at 
building the family resources/resilience to assist the woman during her breast cancer journey. Although the women felt they had adequate care they often wished their family had been included more often in the decision-making process. Several of the women in the study explained that if ward areas were more child friendly such as accessible lounge areas it would be easier for their family to visit. Another concern was the difficulty of having medical, radiotherapy and chemotherapy appointments which could be organised around child care needs.

Most importantly the study highlights the significant psychosocial impact of the cancer diagnosis on younger women. While emotion is expended towards aspects such as loss of fertility and femininity younger women facer a tougher reality in having greater responsibility for the well being of others and in the provision of stability for everyday family life; of having 'to hold it all together' for the sake of dependent others. An increased availability of specialist breast care nurses would allow additional quality time with the younger women discussing how her family is coping with the breast cancer treatment.

Finally, being young with breast cancer highlighted the 'what will I do after treatment' question - raising the notion of quality of life and reappraisal of life goals. These are issues that need to be acknowledged by health professionals when caring for young women with breast cancer and the family. Continued support which is individually tailored for the young woman's phase of life is essential for the young woman and her family even after discharge from medical treatment to ensure they adjust to this changed life sequel.

\section{Study Limitations and future research}

The generalization of qualitative research is limited and caution should be exercised when transferring findings reported from this study to other contexts. As in the case in qualitative research sample size is small. Future research might consider participants from different cultural backgrounds taking into account families' and health professional perspectives. As individuals and their families continue to live and survive longer with chronic illness (cancer), quality of life of the family becomes a critical issue thus needing future research. Women's experience of the breast cancer 
trajectory as they move into long term survival is therefore another important area for research.

\section{Acknowledgment}

This study was funded by a scholarship from the Queensland Nursing Council (SAN 0467). The author would like to acknowledge and thank the women who shared their experiences for this study.

\section{References}

AIHW (2005) Australian Institute of Health and Welfare. Accessed at http://www.aihw.gov.au/ on 15 February 2005.

Becker HS (2005) 'The epistemology of qualitative research'. Accessed at http://home.earthlinl.net/ hsbecker/qa.html on 1 April 2005.

Bloom JR, Stewart SL, Chang S and Banks PJ (2004) Then and now: quality of life of young breast cancer survivors. Psycho-Oncology 13: 147-160.

Bloom JR, Stewart SL, Johnston M, Banks P and Fobair P (2001) Sources of support and the physical and mental well-being of young women with breast cancer. Social Science and Medicine 53(11): 1513-1524.

Carver CS, Smith RG, Antoni MH, Petronis VM, Weiss S and Derhagopian R (2005) Optimistic Personality and Psychosocial Well-Being During Treatment Predict Psychosocial Well-Being Among Long-Term Survivors of Breast Cancer. Health Psychology 24(5): 508-516.

Cohen MZ, Kahn DL and Steeves RH (1998) Beyond body image: The experience of breast cancer. Oncology Nursing Forum 25(5): 835-841.

Compas BE, Worsham NL, Epping-Jordan JE, Grant KE, Mireault G, Howell DC and Malcarne VL (1994) When Mom or Dad Has Cancer: Markers of Psychological

Distress in Cancer Patients Spouses and Children. Health Psychology 13(6) 507-515.

Compas BE, Worsham NL, Ey S and Howell DC (1996) When Mom or Dad Has Cancer: II. Coping, Cognitive Appraisals, and Psychological Distress in Children of Cancer Patients. Health Psychology 15(3): 167-175.

Coyne E (2004) 'I have breast cancer, but it doesn't have me'. Unpublished Master of Nursing Honours, University of Southern Queensland, Toowoomba.

Davis Kirsch SE, Brandt PA and Lewis FM (2003) Making the most of the moment: When a child's mother has breast cancer. Cancer Nursing 26(1): 47-54. 
Dunn J and Steginga SK (2000) Young women's experience of breast cancer:

Defining young and identifying concerns. Psycho-Oncology 9: 137-146.

Emden C (1998) Theoretical perspectives on narrative inquiry. Collegian 5(2), 30-35.

Epping-Jordan JE, Compas BE, Osowiecki DM, Oppedisano G, Gerhardt C, Primo K, and Krag DN (1999) Psychological Adjustment in Breast Cancer: Processes of Emotional Distress. Health Psychology 18(4) 315-326.

Glesne C (1999) Becoming Qualitative Researchers: An Introduction (2nd edn). Sydney: Addison Wesley Longman.

Graf MC and Geller PA (2003) Treating hot flashes in breast cancer survivors: A review of alternative treatments to hormone replacement therapy. Clinical Journal of Oncology Nursing 7(6): 637-640.

Henderson PD, Gore SV, Davis BL and Condon EH (2003) African American women coping with breast cancer: A qualitative analysis. Oncology Nursing Forum 30(4): 641-646.

Hoke LA (2000) Psychological adjustment in children of mothers with breast cancer. Psycho-Oncology 10: 361-369.

Holloway I and Wheeler S (2002) Qualitative research in nursing ( $2^{\text {nd }}$ edn) Oxford: Blackwell Science.

Hutchinson SD, Steginga SK and Dunn J (2006) The tiered model of psychosocial intervention in cancer: a community based approach. Psycho-Oncology 15(6): 541-6. Johnson P (2002) The use of humour and its influences on spirituality and coping in breast cancer survivors. Oncology Nursing Forum 29(4): 691-695.

Knobf TM (2001) The menopausal symptom experience in young mid-life women with breast cancer. Cancer Nursing 24(3): 201-210.

Lather PA (1991) Getting smart Feminist Research and Pedagogy With/in the Postmodern. New York: Routledge.

Liebert B, Parle M, White K and Rodger A (2001) Establishing an evidence base for the specialistic breast nurse: A model for Australian breast cancer care. Australian Health Review 24(1): 192-199.

Mellon S and Northouse L (2001) Family survivorship and quality of life following a cancer diagnosis. Research in Nursing and Health 24(6): 446-459.

National Breast Cancer Centre NBCC (2001a) Clinical practice guidelines management of early breast cancer. Canberra: National Breast Cancer Centre.

National Breast Cancer Centre NBCC (2001b) Psychosocial clinical practice guidelines. Canberra: National Health and Medical Research Council. 
National Breast Cancer Centre NBCC (2003) An evidence-based specialist breast nurse role in practice a mulitcentre implementation study. Journal of Cancer Care 12: 91-97.

Northouse L (2005) Helping families of patients with cancer. Oncology Nursing Forum 32(4): 743-750.

Northouse L, Kershaw T, Mood D and Schafenacker A (2005) Effects of a family intervention on the quality of life of women with recurrent breast cancer and their family caregivers. Psycho-Oncology 14: 478-491.

Parle M, Gallagher J, Gray C, Aker G and Liebert B (2001) From evidence to practice: Factors affecting the specialist breast nurse's detection of psychological morbidity in women with breast cancer. Psycho-Oncology 10: 503-510.

Porter S (1998) Social theory and nursing practice. London: Macmillan press.

Raveis VH and Pretter S (2004) Existential plight of adult daughters following their mother's breast cancer diagnosis. Psycho-Oncology 14: 49-60.

Reinharz S (1992) Feminist interview research. Feminist Methods in Social research: 18-45.

Rogers-Clark C (2002) 'Resilient Survivors: Rural Women Who Have Lived Through Breast Cancer'. Unpublished Doctorate of Philosophy, University of Southern Queensland, Toowoomba.

Shands ME, Lewis FM and Hooper ZE (2000) Mother and child interactions about the mother's breast cancer: an interview study. Oncology Nursing Forum 26(1): 77-85.

Steginga S, Occhipinti S, Wilson K and Dunn J (1998) Domains of distress: The experience of breast cancer in Australia. Oncology Nursing Forum 25(6): 1063-1070.

Strauss AL and Corbin J (1990) Basics of Qualitative Research. Thousand Oaks: Sage.

Thewes B and White K (2005) Psychological aspects of sexuality and fertility after a diagnosis of breast cancer. Cancer Forum 30(1): 6-9.

Turner J, Kelly B, Swanson C, Allison R and Wetzig N (2005) Psychosocial impact of newly diagnosed advanced breast cancer. Psycho-Oncology 14: 396-407.

Walsh SR, Manuel JC and Avis NE (2005) The impact of breast cancer on younger women's relationship with their partner and children. Families, Systems, and Health 23(1): 80-93.

Wilkes L, White K and Beale B (2002) Life after breast cancer: Australian women's stories of support. Collegian 9(2): 22-25. 
Table 1: Demographic snap shot of participants

\begin{tabular}{|c|c|c|c|c|}
\hline Age & $\begin{array}{l}\text { Marital } \\
\text { status }\end{array}$ & Children & Work Status & Treatment \\
\hline $\begin{array}{l}\text { Dawn } \\
29 y r s\end{array}$ & Defacto & Nil & Full time & $\begin{array}{l}\text { Mastectomy } \\
\text { Chemotherapy } \\
\text { Tamoxifen }\end{array}$ \\
\hline $\begin{array}{l}\text { Fay } \\
33 y r s\end{array}$ & Married & $\begin{array}{l}5 \text { years } \\
2 \text { years }\end{array}$ & Part time & $\begin{array}{l}\text { Mastectomy } \\
\text { Chemotherapy } \\
\text { Radiotherapy } \\
\text { Tamoxifen } \\
\text { Breast reconstruction }\end{array}$ \\
\hline $\begin{array}{l}\text { Carrie } \\
34 y r s\end{array}$ & Married & $\begin{array}{l}18 \text { months old } \\
\text { Pregnant when } \\
\text { diagnosed }\end{array}$ & Home mother & $\begin{array}{l}\text { Lumpectomy } \\
\text { Radiotherapy after baby } \\
\text { was born }\end{array}$ \\
\hline $\begin{array}{l}\text { Anne } \\
\text { 40yrs }\end{array}$ & Married & $\begin{array}{l}11 \text { years } \\
8 \text { years }\end{array}$ & Part time & $\begin{array}{l}\text { Lumpectomy } \\
\text { Mastectomy } \\
\text { Chemotherapy } \\
\text { Radiotherapy } \\
\text { Tamoxifen }\end{array}$ \\
\hline $\begin{array}{l}\text { Pat } \\
43 y r s\end{array}$ & Married & $\begin{array}{l}13 \text { years } \\
11 \text { years }\end{array}$ & Part time & $\begin{array}{l}\text { Lumpectomy } \\
\text { Chemotherapy } \\
\text { Radiotherapy } \\
\text { Tamoxifen }\end{array}$ \\
\hline $\begin{array}{l}\text { Joan } \\
43 y r s\end{array}$ & Married & $\begin{array}{l}15 \text { years } \\
13 \text { years }\end{array}$ & Part time & $\begin{array}{l}\text { Lumpectomy } \\
\text { Chemotherapy } \\
\text { Radiotherapy } \\
\text { Tamoxifen }\end{array}$ \\
\hline
\end{tabular}

